Revista Eletrônica em Gestão, Educação e Tecnologia Ambiental Santa

Maria, v. 20, n. 1, jan.-abr. 2016, p. 62-72

Revista do Centro de Ciências Naturais e Exatas - UFSM

ISSN : 22361170

REGET/UFSM

Revista Eletrônica em Gestão, Educação e Tecnologia Ambiental

\title{
Monitoramento de variáveis microbiológicas para avaliação da balneabilidade de uma praia do Norte Catarinense
}

\author{
Microbiological monitoring for assessment of bathing in a beach at North of Santa Catarina
}

\author{
Alex S. Baucke ${ }^{1}$ Patrícia H. Zambão² e Maria Pilar Serbent ${ }^{3}$ \\ 1; 2 Graduando do curso de Engenharia Sanitária, Universidade do Estado de Santa Catarina (UDESC), Ibirama, SC, Brasil \\ 2 Professora do Dep. de Engenharia Sanitária, Universidade do Estado de Santa Catarina (UDESC), Ibirama, SC, Brasil
}

\begin{abstract}
Resumo
As ações antrópicas decorrentes do grande fluxo de turistas em regiões litorâneas além de causar impactos negativos ao meio ambiente representam um risco aos usuários já que podem estar associadas a problemas de saúde pública. Com o objetivo de avaliar a balneabilidade de uma praia no norte catarinense, no município de Penha - SC, entre novembro de 2014 e março de 2015 coletaram-se amostras de água em oito pontos, a fim de verificar a contaminação da água do mar em função da proximidade com as línguas negras visando comparar estes resultados com as considerações feitas pelo o órgão ambiental do estado de Santa Catarina. A partir dos resultados obtidos, observou-se contaminação microbiológica da água nos locais onde foram realizadas as coletas devido à presença de E. coli, importante indicador de contaminação fecal. Os resultados deste trabalho demonstraram uma considerada discrepância nos valores de E. coli entre os pontos $e$ períodos coletados. Assim, sugere-se a necessidade de um maior número de amostras para o monitoramento da qualidade da água, principalmente na época com grande fluxo de turistas, a fim de evitar problemas posteriores de saúde pública. Por fim, entende-se que o presente trabalho não pode caracterizar apropriadamente a balneabilidade ou não da praia em estudo, devido ao curto período de pesquisa. Entretanto, o trabalho conjunto dos órgãos ambientais e as universidades podem conduzir a melhores informações para a população em relação às condições de banho das áreas litorâneas.
\end{abstract}

Palavras-chave: Balneabilidade. Análises microbiológicas. Turismo.

\begin{abstract}
The human actions arising from influx of visitors in coastal regions may be associated to public health problems and negative effects to the environment. In this sense, microbiological analysis of water samples were developed on a beach in north Santa Catarina, located in the municipality of Penha. To verify the sea water for contact primary to recreation and to have a monitoring data basis, the considerations made by environmental agency of State of Santa Catarina were analyzed complementarily. The study happened in November of 2014 and January/ March of 2015. The water collection it occurred on eight points along the Penha's Beach. The points are salty water (sea) and wastewater disposal on the sand. Throughout the study, microbiological contamination was observed due to the presence of Escherichia coli, an important indicator of fecal contamination, in the places where sampling of the water and exposed wastewater at the edge of the beach were performed. The results obtained showed discrepancy in values of E. coli between points and collected periods. Thus, it is suggested the need for a larger number of samples for monitoring water quality, especially at the time with great flow of tourists in order to avoid problems of public health as a water borne diseases. Finally, it is understood that this work can not characterize properly the bathing conditions, due to the short period of study. However, the joint work of environmental agencies and universities may lead to better information regarding bathing conditions at coastal areas available to the public.
\end{abstract}

Keywords: Bathing, Microbiological analysis, tourism. 


\section{Introdução}

As áreas litorâneas brasileiras, assim como as catarinenses, estão cada vez mais suscetíveis às ações antrópicas, principalmente nos meses de dezembro a março, devido ao turismo. As diversas ações protagonizadas pelo homem, de caráter prejudicial ao meio ambiente, abrangem a supressão da vegetação e da fauna litorânea, o acúmulo de resíduos sólidos e o escoamento de águas residuárias das residências, que na maioria dos casos apresentam apenas tratamento individual.

O grande impacto das águas residuais provenientes do sistema de drenagem municipal tem sido destacado já que estas recebem além das águas da chuva o esgoto doméstico sem tratamento coletivo e deságuam no mar, sendo conhecidas popularmente como línguas negras (RODRIGUES et al. 2012).

No estado de Santa Catarina, o órgão responsável pela caracterização de locais próprios para banho é a Fundação do Meio Ambiente (FATMA). Considerando que o turismo no litoral do estado de Santa Catarina destaca-se como importante fonte geradora de recursos e que o município de Penha recebe um grande número de visitantes nos períodos de temporada, verão, o presente estudo de caso realizou-se com o intuito de verificar a balneabilidade desta praia do litoral catarinense antes, durante e depois do período de maior presença de turistas. A pesquisa desenvolveu-se na Praia de Armação, no município de Penha - SC, nos meses de novembro de 2014, janeiro e março de 2015, onde foram escolhidos oito pontos para a realização de coleta de amostras de água para análise da contaminação microbiológica devido às interações antrópicas ao longo da orla da praia, tendo como critério a abrangência dos locais mais utilizados pelos visitantes e a presença de línguas negras. Atualmente, a orla do município de Penha constitui-se em uma das áreas mais conflituosas quanto ao uso do solo e do mar do litoral centro-norte de Santa Catarina devido à ocupação urbana desordenada, bem como devido a inúmeros conflitos gerados entre a pesca artesanal, a maricultura, a navegação de recreio e a pesca industrial, o que gerou inúmeros conflitos de interesses sociais, econômicos, políticos e conservacionistas (Polette e Silva, 2006).

\section{Balneabilidade no estado de Santa Catarina}

Os Sistemas de monitoramento da Balneabilidade estão baseados em metodologias de acompanhamento da qualidade das águas, onde se verifica a presença ou ausência de contaminação microbiológica nas águas costeiras, os quais são representados por microrganismos do grupo dos coliformes, geralmente existentes nas excretas de animais de sangue quente que podem colocar em risco a saúde da população presente nesses ambientes (NEMETZ, 2004).

Os parâmetros microbiológicos para assegurar a qualidade das áreas litorâneas para contato primário, isto é, as áreas de uso dos banhistas são descritos na Resolução CONAMA n ${ }^{\circ} 274$, de 29 de novembro de 2000 (BRASIL, 2000). O Ministério da Saúde, através da Resolução no 12, de 2 de janeiro de 2001, da Agência Nacional de Vigilância Sanitária (ANVISA) adotou a denominação coliformes a $45^{\circ} \mathrm{C}$, considerando os padrões "coliformes de origem fecal" e "coliformes termotolerantes" como equivalentes a coliformes a $45^{\circ} \mathrm{C}$. Nesse sentido, o parâmetro coliformes a $45^{\circ} \mathrm{C}$ demonstra-se como um indicativo eficiente de contaminação, onde está intrinsecamente relacionado à saúde pública, bem como relacionado a eficiência dos sistemas de esgotamento sanitário da região.

Entre as áreas atingidas pela poluição antrópica, destacam-se as praias. Os processos de degradação das praias podem ocasionar riscos ambientais graves, como problemas de saúde pública ligada ao contato com organismos patógenos ou destruição das áreas de preservação permanente (APP). Como exemplo pode ser citado o caso das restingas, que de acordo com a Resolução CONAMA $n^{\circ}$ 261, de 30 de junho de 1999, podem ser definidas como um conjunto de comunidades vegetais edáficas e estruturalmente distintas, que compreendem formações herbáceas, subarbustivas, arbustivas ou arbóreas (BRASIL, 1999). Este tipo de vegetação é encontrada em terrenos arenosos, e possuem grande importância na estabilização de sedimentos, preservação da fauna e manutenção da drenagem natural. 
Os avanços na agricultura e principalmente a crescente ocupação urbana nas áreas litorâneas brasileiras, que em 2002 chegou a atingir $87 \mathrm{hab} / \mathrm{km}^{2}$, promoveram a supressão da cobertura vegetal desses locais, principalmente na Mata Atlântica (THOMAZI et al. 2013).

Por outro lado, as praias são frequentemente utilizadas como ponto de despejo de efluentes líquidos, onde o efluente, diversas vezes, não recebe tratamento algum. Neste contexto, o monitoramento da qualidade das águas nas praias adquire importância, visto que a sua contaminação poderá gerar inúmeros problemas sociais e econômicos.

No estado de Santa Catarina, o órgão responsável pelo monitoramento da balneabilidade é a Fundação do Meio Ambiente (FATMA), a qual intensifica suas análises nos períodos de novembro a março, realizando verificações semanais em diversos pontos ao longo da costa catarinense. Nos meses que não representam alta temporada, é realizada apenas a análise mensal dos pontos. A FATMA, para melhor divulgar a população sobre pontos próprios e impróprios para banho, criou e disponibilizou recentemente um aplicativo para celulares e tablets que auxilia os banhistas na escolha dos locais para lazer conforme a qualidade da água. Os resultados são de acesso público pelo site da FATMA ou mediante aplicativo para celulares e tablets, disponibilizado pelo órgão na plataforma Android, o qual poderá ser verificar a balneabilidade de 199 pontos do litoral catarinense (FATMA, 2015).

A atividade turística em Penha/SC vem se expandindo através do potencial atrativo pelas opções de praias (Goulart e Teixeira, 2005), com águas calmas ou agitadas, ainda relativamente conservadas, e também em função da implantação do centro de lazer "Complexo Turístico Beto Carrero World", que recebe turistas o ano todo, incentivando o setor comercial, principalmente o hoteleiro, promovendo, consequentemente, a ocupação da área e a especulação imobiliária (Marenzi, 1996). A faixa litorânea é ocupada, na maioria, com residências de médio a alto padrão, muitas de propriedade de veranistas, ocorrendo uma expansão para as encostas dos morros que acompanham a orla marítima. Parte desta faixa contém avenida beira-mar e em alguns pontos aparecem saídas de esgoto a céu aberto (Marenzi, 1996).

No município de Penha, o abastecimento de água e os serviços de coleta e tratamento de esgoto são de responsabilidade da autarquia municipal "Águas do Itapocoróy". O órgão regulador da prestação de serviços é a Agência Reguladora Intermunicipal de Saneamento (ARIS), que atua no município desde 2011.

No presente estudo, buscou-se avaliar a influência das línguas negras na qualidade das águas salinas da orla da Praia de Armação, Penha/SC, aonde desembocam antes, durante e depois do período de maior fluxo de turistas na região da temporada de verão do ano 2015.

\section{Materiais e métodos}

O município escolhido, Penha - SC, no litoral norte, conta com aproximadamente 19 praias, em uma área de $58.783 \mathrm{~m}^{2}$. A população ao longo do ano varia, devido à sazonalidade litorânea, entretanto 25.140 pessoas residem permanentemente na cidade. Porém, no verão, Penha pode atingir uma população superior a 120mil pessoas. Com predominância da cultura açoriana, o município é sede da Festa Nacional do Marisco. Destaca-se, como um forte ponto turístico da cidade, o Parque de Diversões Beto Carreiro World.

A região onde se desenvolveu o estudo foi a Praia de Armação, a qual corresponde a uma área histórica do município, considerada como Zona especial de Ocupação Tradicional de acordo com a Lei complementar № 2/07 (Penha, 2014). Foram escolhidos oito pontos para a coleta e análise microbiológica. Os pontos de coleta ímpares $(1,3,5,7)$, foram realizados ao longo de um trecho de aproximadamente $1 \mathrm{~km}$, nas águas residuais provenientes do sistema de drenagem municipal, também conhecidas como línguas negras (RODRIGUES et al. 2012). Já os pontos pares $(2,4,6,8)$, são locais em linha reta com os despejos, porém dentro do mar. No Quadro 01 são descritos os pontos de coleta com suas respectivas coordenadas geográficas. 


\begin{tabular}{|c|c|c|}
\hline Ponto & Coordenadas & Local \\
\hline \multirow{2}{*}{$\begin{array}{c}\text { Ponto } \\
01\end{array}$} & S: $26^{\circ} 46.992^{\prime}$ & \multirow{2}{*}{$\begin{array}{l}\text { Língua } \\
\text { Negra }\end{array}$} \\
\hline & $\mathrm{W}: 048^{\circ} 37.821^{\prime}$ & \\
\hline \multirow{2}{*}{$\begin{array}{c}\text { Ponto } \\
02\end{array}$} & S: $26^{\circ} 46.992^{\prime}$ & \multirow{2}{*}{ Mar } \\
\hline & $\mathrm{W}: 048^{\circ} 37.821^{\prime}$ & \\
\hline \multirow{2}{*}{$\begin{array}{c}\text { Ponto } \\
03\end{array}$} & S: $26^{\circ} 46.830^{\prime}$ & \multirow{2}{*}{$\begin{array}{l}\text { Língua } \\
\text { Negra }\end{array}$} \\
\hline & $\mathrm{W}: 048^{\circ} 37.982^{\prime}$ & \\
\hline \multirow{2}{*}{$\begin{array}{c}\text { Ponto } \\
04\end{array}$} & S: $26^{\circ} 46.830^{\prime}$ & \multirow{2}{*}{ Mar } \\
\hline & W: 048 37.982' & \\
\hline \multirow{2}{*}{$\begin{array}{c}\text { Ponto } \\
05 \\
\end{array}$} & S: $26^{\circ} 47.059^{\prime}$ & \multirow{2}{*}{$\begin{array}{l}\text { Língua } \\
\text { Negra }\end{array}$} \\
\hline & $\mathrm{W}: 048^{\circ} 37.737^{\prime}$ & \\
\hline \multirow{2}{*}{$\begin{array}{c}\text { Ponto } \\
06\end{array}$} & S: $26^{\circ} 47.059^{\prime}$ & \multirow{2}{*}{ Mar } \\
\hline & W: $048^{\circ} 37.737^{\prime}$ & \\
\hline \multirow{2}{*}{$\begin{array}{c}\text { Ponto } \\
07\end{array}$} & S: $26^{\circ} 47.156^{\prime}$ & \multirow{2}{*}{$\begin{array}{l}\text { Língua } \\
\text { Negra }\end{array}$} \\
\hline & $\mathrm{W}: 048^{\circ} 37.611^{\prime}$ & \\
\hline \multirow{2}{*}{$\begin{array}{c}\text { Ponto } \\
08\end{array}$} & S: $26^{\circ} 47.156^{\prime}$ & \multirow{2}{*}{ Mar } \\
\hline & W: $048^{\circ} 37.611^{\prime}$ & \\
\hline
\end{tabular}

Quadro 01 - Localização dos pontos de coleta de água.

Neste estudo, os pontos de coleta foram escolhidos para uma melhor análise da contaminação antrópica ao longo da praia, de acordo com os critérios descritos anteriormente, visto que as línguas negras desembocam, sem tratamento no mar. Ainda, o período da pesquisa ocorreu nos meses de novembro de 2014, janeiro e março do ano de 2015. As datas das coletas e análises foram selecionadas devido à variação de sazonalidade populacional durante o período de verão nas áreas litorâneas.

Devido à falta de conhecimento sobre as correntes marítimas da localidade de Penha, efetuou-se a coleta das amostras em linha reta com os efluentes que adentram no mar (línguas negras), na seção com maior fluxo destes efluentes.

A amostragem foi efetuada conforme a altura da lâmina da água das línguas negras e para a água do mar respeitou-se uma isóbata de um metro, sendo que a retirada da água realizou-se entre 15 a 30 centímetros conforme instrução do Manual Técnico para Coleta de Amostras de Água (2009). Imediatamente após a coleta, as amostras foram colocadas ao abrigo de luz solar, refrigeradas a aproximadamente $4^{\circ} \mathrm{C}$ e identificadas com o ponto de amostragem e sua localização.

Na Figura 01 abaixo, são mostrados os pontos de coleta para a análise microbiológica ao longo da orla da Praia de Armação. 


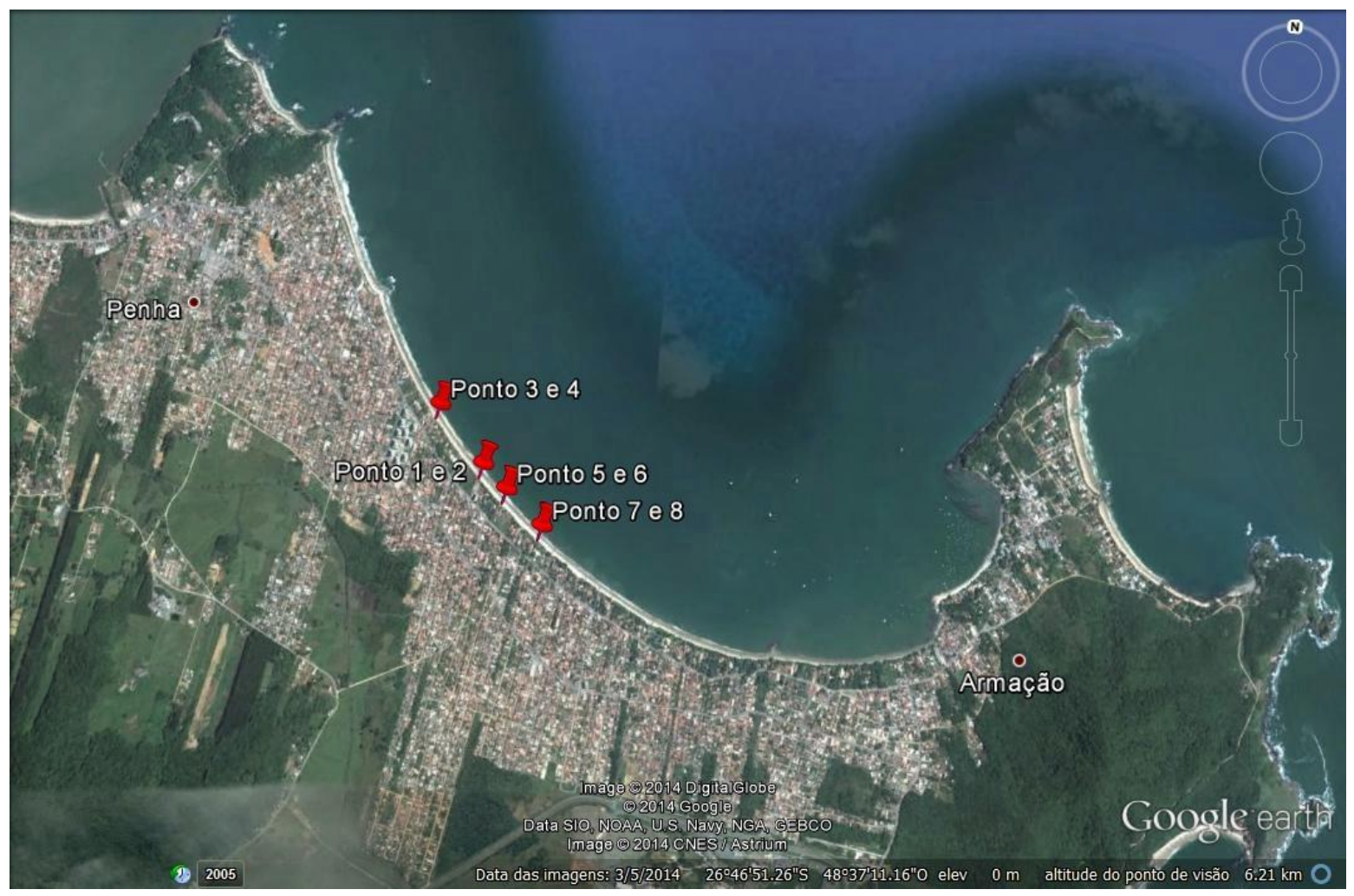

Figura 01 - Pontos de coleta e sua localização na orla da praia de Armação. Fonte: (GOOGLE, 2014).

Nos locais de amostragem, realizaram-se também outras observações referentes à influência antrópica, como presença de resíduos sólidos, existência de lixeiras e estado das mesmas.

Considerando os objetivos deste trabalho, analisaram-se também os dados disponibilizados pela FATMA em relação à balneabilidade.

De acordo com o site da FATMA, os 195 pontos de coleta de amostras de água do mar distribuídos nos 500 quilômetros de costa catarinense, não obedecem a um padrão de metragem, ou seja, distância entre uma amostra e outra. Entretanto, priorizam-se os locais com maior fluxo de banhistas, que normalmente são locais mais suscetíveis a poluição.

No município de Penha, são avaliados por esta entidade onze pontos para balneabilidade, sendo três compreendidos ao longo da orla de Armação. É importante destacar que as análises das línguas negras não são realizadas pela entidade ambiental, visto que são de responsabilidade da concessionária municipal de saneamento, o tratamento dos efluentes gerados no município e a verificação de seus possíveis vazamentos de adutoras e elevatórias de efluentes. Porém, como o município conta com apenas o tratamento individual, torna-se incerta a verificação de possíveis despejos de efluentes na rede de drenagem sem o devido tratamento.

Na Figura 02, apresentam-se os pontos de coleta da FATMA na orla da Praia de Penha, onde se realizou este estudo. 


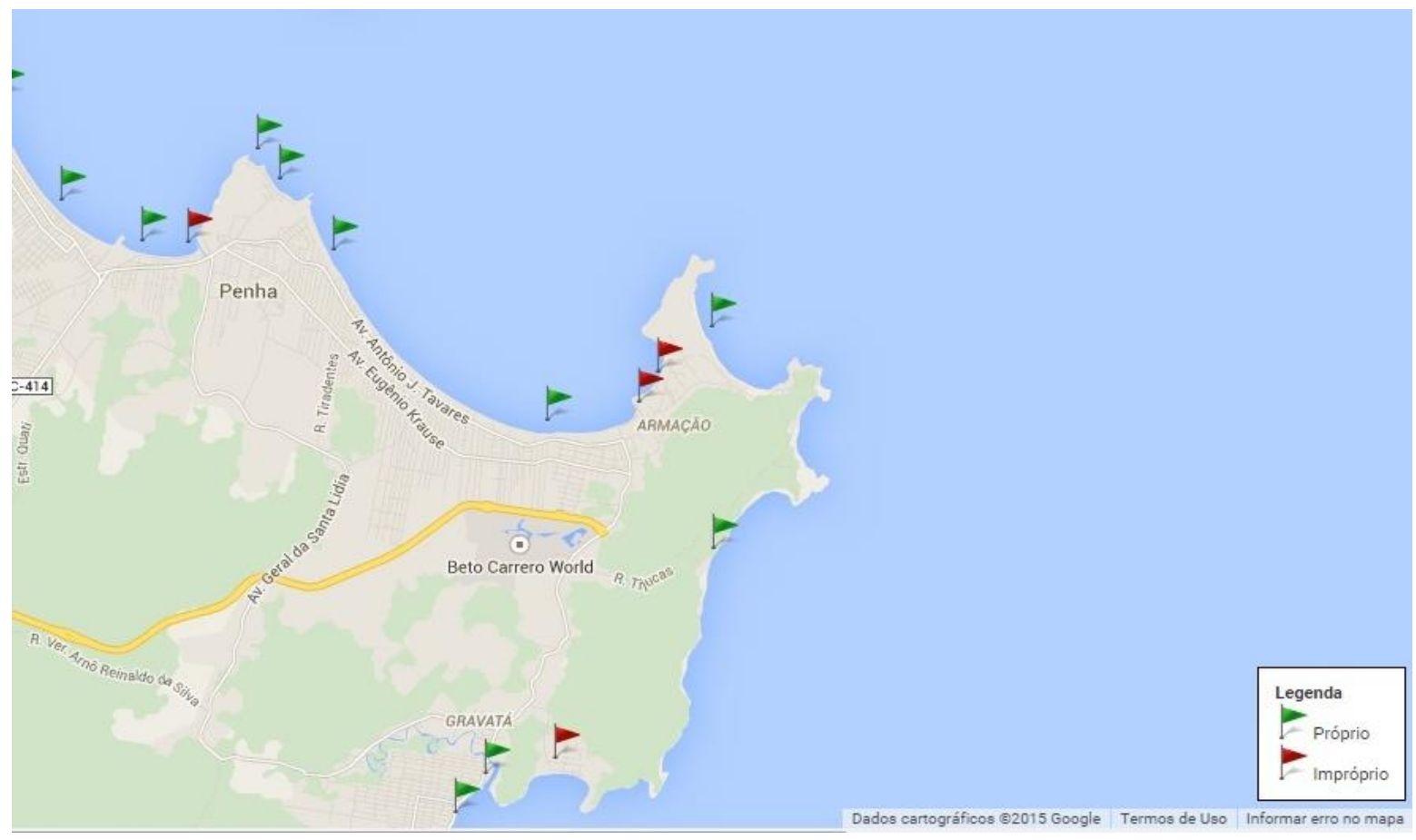

Figura 02 - Pontos de coleta da FATMA.

Fonte: FATMA (2015)

\subsection{Análises microbiológicas}

As análises da presença de coliformes totais e Escherichia coli realizaram-se com o método do substrato cromogênico, de acordo com as instruções do Standard Methods for Examination of Water and Wastewater (APHA, 2005). As amostras foram coletadas em frascos de vidro esterilizados e transferidas, no laboratório, para as cartelas com meio de cultura. No laboratório, adicionaram-se $1 \mathrm{ml}$ da amostra a $99 \mathrm{ml}$ de água estéril para as amostras ímpares, devido à carga orgânica das amostras. Para os pontos pares, não foi necessário realizar a diluição, dessa forma, utilizou-se o volume 100ml da amostra coletada. Em seguida, adicionou-se o reagente, homogeneizamos a amostra e a distribuímos em cartelas, selando-as e incubando na estufa a $35^{\circ} \mathrm{C}$ durante $24 \mathrm{~h}$. Após esse período observou-se a presença de bactérias do grupo coliformes mediante a mudança de cor para o amarelo forte (indicando presença de coliformes totais) e da emissão de fluorescência quando exposta à luz ultravioleta (indicando presença de Escherichia coli). 


\section{Resultados e Discussão}

\subsection{Análise Microbiológica}

No Quadro 02 abaixo são mostrados os resultados obtidos para coliformes a $45^{\circ} \mathrm{C}$ em todos os pontos analisados.

\begin{tabular}{|l|l|c|c|c|}
\cline { 2 - 5 } \multicolumn{1}{c|}{} & Período & nov/14 & jan/15 & mar/15 \\
\cline { 2 - 5 } \multicolumn{1}{c|}{} & Resultado & $\mathrm{NMP} / 100 \mathrm{ml}$ & $\mathrm{NMP} / 100 \mathrm{ml}$ & $\mathrm{NMP} / 100 \mathrm{ml}$ \\
\hline \multirow{4}{*}{} & Ponto 01 & 241960 & 483920 & 3280 \\
\cline { 2 - 5 } & Ponto 02 & 35 & 29,2 & 290,9 \\
\cline { 2 - 5 } & Ponto 03 & 155310 & 209240 & 7360 \\
\cline { 2 - 5 } & Ponto 04 & 36,9 & 32,3 & 117,8 \\
\cline { 2 - 5 } & Ponto 05 & 15150 & 240660 & 1440 \\
\cline { 2 - 5 } & Ponto 06 & 18,9 & 24,3 & 128,1 \\
\cline { 2 - 5 } & Ponto 07 & 13960 & 2180 & 1240 \\
\cline { 2 - 5 } & Ponto 08 & 24,6 & 12,1 & 65,7 \\
\hline
\end{tabular}

Quadro 02 - Análise de coliformes de pontos da praia de Armação.

*Número Máximo Provável (NMP)

A partir os resultados pode-se observar que os pontos ímpares apresentam valores elevados do $\mathrm{NMP} / 100 \mathrm{ml}$ de coliformes quando comparados aos pontos pares, já que os primeiros representam as línguas negras, nos quais há indícios visuais e olfativos característicos de descartes indevidos de esgoto provindos da cidade, a qual não possui tratamento coletivo. Já os pontos pares referem-se aos pontos no mar, onde a diluição dos efluentes domésticos estaria demonstrada pelo menor valor de coliformes (Tabela 2).

No Quadro 03, apresentam-se os dados de coleta e análise da balneabilidade em locais próximos aos da coleta da pesquisa.

\begin{tabular}{|l|c|c|c|c|c|c|c|c|c|}
\cline { 2 - 9 } \multicolumn{1}{c|}{} & \multicolumn{2}{c|}{$\begin{array}{c}\text { Novembro } \\
\text { NMP/100ml }\end{array}$} & Média & \multicolumn{2}{c|}{$\begin{array}{c}\text { Janeiro } \\
\text { NMP/100ml }\end{array}$} & Média & \multicolumn{2}{c|}{$\begin{array}{c}\text { Março } \\
\text { NMP/100ml }\end{array}$} & Média \\
\hline $\begin{array}{l}\text { Ponto 03 } \\
\text { (FATMA) - } \\
(1,2,3,4)\end{array}$ & 10 & 10 & $\mathbf{1 0}$ & 52 & 94 & 73 & 20 & 62 & $\mathbf{4 1}$ \\
\hline $\begin{array}{l}\text { Ponto 04 } \\
\text { (FATMA) - } \\
(5,6,7,8)\end{array}$ & 134 & 279 & $\mathbf{2 0 6 , 5}$ & 318 & 8664 & $\mathbf{4 4 9 1}$ & 52 & 345 & $\mathbf{1 9 8 , 5}$ \\
\hline
\end{tabular}

Quadro 03 - Resultados das análises microbiológicas da FATMA.

Fonte: adaptado de FATMA (2015)

Dessa forma, podem-se aliar os resultados obtidos aos dados disponibilizados pela FATMA em relação a análises de balneabilidade.Destaca-se que o programa de monitoramento do órgão ambiental para qualidade da água para fins de balneabilidade poderia ser complementado com mais pontos de coleta ao longo da costa catarinense visto que o fluxo de turistas na região durante o veraneio atinge taxas elevadas e a saúde pública torna-se um constante problema aos municípios.

Observa-se que o ponto 3 definido pela FATMA está próximo aos quatro primeiros pontos escolhidos pela pesquisa. Já o ponto 4, está localizado próximo aos quatro últimos pontos da pesquisa. Assim, nota-se uma proximidade nos valores encontrados nesta pesquisa e os resultantes do monitoramento realizado pela FATMA para o ponto 3, quando analisado os pontos ao mar, ou seja, onde é realizada a análise para enquadramento da balneabilidade. Já para o ponto 4 percebe-se uma 
notável diferença, que pode ser devido ao ponto de coleta utilizado pela FATMA, localizar-se mais ao sul da orla, onde visualmente verifica-se índices maiores de poluição, além de uma ocupação pesqueira mais acentuada.

Com os dados obtidos durante os três meses de pesquisa, foram gerados gráficos da contaminação microbiológica. No Gráfico 01, demonstram-se os resultados obtidos para cada ponto de coleta bem como o número máximo provável por 100 mililitros (NMP/100ml).

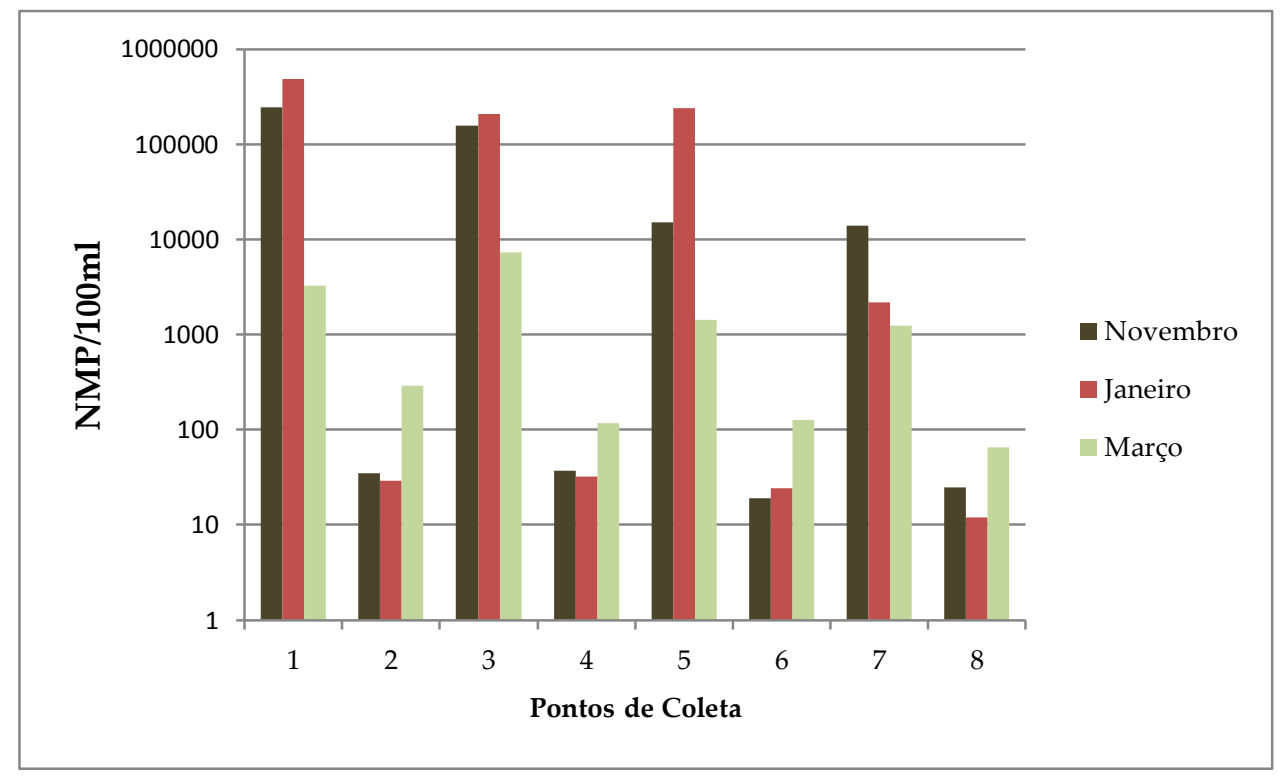

Gráfico 01 - Contaminação por Escherichia coli nos pontos de coleta.

Destaca-se que relacionado à Resolução $n^{\circ}$ 274/2000, sobre balneabilidade, seriam necessário maiores períodos de coleta para obtenção de valores significativos. Ainda, segundo a legislação, para uma água satisfatória seriam necessários $80 \%$ ou mais das amostras ou conjuntos de amostras, no período de cinco semanas coletados no mesmo local, apresentarem no máximo $800 \mathrm{NMP} / 100 \mathrm{ml}$ de Escherichia coli. Assim como, para se considerar impróprio o local a última amostragem apresentar valores superiores a $2000 \mathrm{NMP} / 100 \mathrm{ml}$ de Escherichia coli. Deste modo, deve-se avaliar de forma concisa as amostras e verificar a possível existência de condições satisfatórias ou impróprias para contato primário, lazer, entre outras atividades. Nos pontos de coleta próximo ao mar, notam-se valores muito elevados de contaminação por Escherichia coli. Já nos pontos coletados dentro do mar, os valores apresentam-se baixos se comparados aos outros, fator esse que pode estar associado a possíveis diluições e plumas de dispersão no mar dessa contaminação microbiológica.

Nos estudos realizados por SATO et al. (2005) em praias de São Paulo, também se verificou uma maior incidência de coliformes a $45^{\circ} \mathrm{C}$ na água do mar no período de alto fluxo de banhistas, ou seja, no verão. Ainda, a pesquisa ressaltou que a contaminação das areias que não possuem contato com as águas salinas, chegou a ser consideravelmente maior que na água do mar, evidenciando a grande contribuição que as línguas negras e os córregos poluídos podem trazer na qualidade das praias.

Além da contaminação provocada pelos despejos domésticos, no decorrer do processo de coleta de amostras, foram detectadas várias influências antrópicas na área, mesmo se tratando de uma cidade considerada pequena. Foram verificadas grandes quantidades de resíduos sólidos espalhados pela orla, além de contar com os lixeiros existentes completamente abarrotados, mostrando certo descaso da administração pública municipal. As consequências do turismo têm sido abordadas por outros autores. Pires (2010), afirma que esta atividade "inevitavelmente, produz resíduos sólidos e efluentes orgânicos (esgotos), e a má disposição ou destinação final dos mesmos é um sério problema, principalmente em áreas com alta concentração de turistas. [...]". 


\section{Conclusão}

Conclui-se com o estudo, que os pontos de coleta onde se localizavam os despejos, as áreas de línguas negras, observaram-se os valores mais elevados quando comparados aos pontos localizados no mar. Assim, nota-se uma elevada influência humana nessa região, onde há o despejo de efluentes domésticos sem tratamento via línguas negras no mar, que pode estar atrelado à falta de fiscalização do órgão competente, ausência de investimentos em saneamento básico, além de evidenciar o descaso da administração com o setor de saúde pública e turística da região.

As análises das línguas negras não são realizadas pela entidade ambiental, visto que a responsabilidade cabe à empresa prestadora de serviços do município, que deve identificar os pontos de despejos domésticos e vazamentos de efluentes, aplicando as medidas necessárias. Porém, em conjunto a concessionária, prefeitura e FATMA, poderiam desenvolver programas de análise para auxiliar a região no mapeamento das localidades com maior despejo de efluentes sem tratamento coletivo, e assim fornecer subsídios para diminuir as fontes de contaminação da água do mar.

Por fim, destaca-se a necessidade de maiores períodos de pesquisa para a produção de dados mais significativos, visto que a legislação referente à balneabilidade exige coleta e análise microbiológica num espaço temporal maior que o do presente trabalho. Porém, ressalta-se que o estudo das influências antrópicas nos variados períodos do ano, principalmente nesta área sensível a ocupação humana, torna-se uma boa ferramenta de gestão costeira ambiental. Mas, de acordo com os resultados encontrados nas análises de balneabilidade dos quatro pontos analisados na orla da praia de Armação, em todos os meses da pesquisa os pontos estiveram abaixo do limite de $800 \mathrm{NMP} / 100 \mathrm{ml}$, demonstrando-se aptos a utilização por parte da comunidade e para os turistas na recreação em contato primário. Ainda, o tema balneabilidade torna-se por diversas vezes, um tema árduo perante os municípios (prefeituras) da região costeira, principalmente durante a época de veraneio, onde há a maior preocupação em fornecer água potável e energia elétrica a população e por vezes, não há avaliação de outros perigos associados ao aumento populacional, como incrementos de vazão de despejos domésticos.

Dessa forma, avaliar e monitorar a região com intenso fluxo de turista pode trazer economia aos municípios sujeitos a sazonalidade populacional, pois quando investe-se em saneamento reduz-se os gastos com saúde.

Ainda, propõe-se um efetivo monitoramento dos parâmetros de balneabilidade pelos órgãos responsáveis bem como maior cumprimento das legislações ambientais existentes. Dessa forma, podese efetivamente reduzir a poluição das praias mediante a fiscalização de despejos indevidos de efluentes domésticos e buscando junto a concessionária de águas municipal a implantação de sistemas eficientes de coleta e tratamento de esgoto para melhor controle dos impactos provocados por atividades antrópicas sobre o meio ambiente.

Para finalizar, destaca-se que o órgão ambiental mediante um programa de metas poderia prever o aumento nos pontos de monitoramento da qualidade da água, de modo a englobar maiores áreas. Ainda, destacam-se os estudos associados à dispersão de contaminantes no meio aquático, os quais podem auxiliar na otimização dos pontos de monitoramento, bem como incentivar desenvolvimento de pesquisas correlacionadas ao tema. Outro ponto a se destacar é a possibilidade de estudos futuros atrelarem a qualidade da areia com os despejos de esgotos realizados a céu aberto, cujo contato com o ser humano pode afetar de forma drástica a saúde da população presente nesses locais de lazer, com doenças de pele, fungos, doenças do trato intestinal, entre outras. Vale ressaltar que, a educação ambiental também é fator decisivo nas questões ambientais, visto que somente pessoas com consciência ambiental são capazes de preservar e conservar os recursos ambientais disponíveis. 


\section{Referências}

APHA, AWWA, WEF. Standard Methods for the examination of water and wastewater. Washington, EUA. 2005.

BRASIL. Ministério do Meio Ambiente. Conselho Nacional do Meio Ambiente. Resolução no 261,de 30 de junho de 1999. Parâmetros básicos para análise dos estágios sucessivos de vegetação de restinga para o Estado de Santa Catarina. Brasília (Brasil), 1999.

BRASIL. Ministério do Meio Ambiente. Conselho Nacional do Meio Ambiente. Resoluçãonº 274, de 29 de novembro de 2000. Define os critérios de balneabilidade em águas brasileiras. Brasília (Brasil), 2000.

BRASIL. Ministério da Saúde. Resolução no 12, de 2 de janeiro de 2001, da Agência Nacional de Vigilância Sanitária (ANVISA). Aprova o Regulamento Técnico sobre padrões microbiológicos para alimentos. Brasília (Brasil), 2001.

Fundação do Meio Ambiente (FATMA) - Balneabilidade. Florianópolis: Fundação do Meio Ambiente. Aplicado; 2015 Ago 10. Disponível em: http://www.fatma.sc.gov.br/conteudo/balneabilidade

GOOGLE EARTH (2014) - DigitalGlobe. Disponível em: https://earth.google.com/

Goulart MK, Teixeira SK. Estudo da percepção do meio ambiente na praia de Armação do Itapocorói, Penha, SC. In: Seminário Nacional sobre Geografia, Percepção e Cognição do Meio Ambiente, 2005, Londrina, PR. Anais do Seminário Nacional sobre Geografia, Percepção e Cognição do Meio Ambiente, 2005.

Instituto Brasileiro de Geografia e Estatística (IBGE). Indicadores de desenvolvimento sustentável: Dimensão ambiental - Oceanos, mares e áreas costeiras. Rio de Janeiro, Brasil, 2004. Disponível em: http://www.ibge.gov.br/home/geociencias/recursosnaturais/ids/defaulttab.shtm

Marenzi, RC. Estudo da Valoração da Paisagem e Preferências Paisagísticasno Município da Penha SC. Curitiba, 1996. 119 p. Dissertação (Mestrado em Conservação da Natureza) - Setor de Ciências Agrárias, Universidade Federal doParaná.

Ministério Público De Santa Catarina. Manual Técnico para Coleta de Amostras de Água. Florianópolis (Brasil): Ministério Público, 2009. Disponível em: http://www.aris.sc.gov.br/download/c210ZV9iaWJsaW9fZG93bjsyMjtsaXZyby1tYW51YWwtdGVjb mljby1wYXJhLWNvbGV0YS1kZS1hbW9zdHJhcy1kZS1hZ3VhLW1wLXNjLnBkZg==.

Nemetz, SMMCCS. Balneabilidade de praias do litoral centro-norte de santa catarina: estudo de percepção ambiental [dissertation]. Blumenau: Fundação Universidade Regional de Blumenau (FURB); 2004.

Penha. Lei Complementar № 2/07, Institui o Código Urbanístico. 2014. https://leismunicipais.com.br/plano-diretor-penha-sc

Polette, M, Silva, LN. Análise socioambiental da orla da Armação do Itapocoroy, Penha: bases para o ordenamento marinho segundo uma visão interinstitucional, cap. 20. In:Branco JO, Marenzi AWC. Bases ecológicas para um desenvolvimento sustentável: estudos de caso em Penha, SC. Itajaí, Universidade do Vale do Itajaí, p. 279-292, 2006.

Pires, PS. In:__. Philippi Jr A, Ruschmann DVM. Turismo e meio ambiente: relação interdependência. In.___ Gestão ambiental e sustentabilidade no turismo. Ed. Barueri, São Paulo: Manole, p. 3-29, 2010.

Rodrigues BT, Bastos AL, Rodrigues MT. Identificação das Línguas Negras provenientes das Galerias Pluviais e bacias hidrográficas nas praias urbanas de Maceió-AL. In: VII CONNEPI [internet]; 2012 
Oct 19-21; Palmas, Brasil. 2012 [cited 2015 jun 14] Disponível em: http://propi.ifto.edu.br/ocs/index.php/connepi/vii/paper/view/2300.

Sato MIZ, Di Bari M, Lamparelli CC, Truzzi AC, Coelho MCLS, Hachich EM. - Sanitary quality of sands from marine recreational beaches of São Paulo, Brazil. Rev. Eletr. Brazilian Journal of Microbiology [Internet]. 2005 [cited 2015 ago 05]; Disponível em: http://www.sbmicrobiologia.org.br/BJM.html

Thomazi RD, Rocha RT, Oliveira MV, Bruno AS, Silva AG. Um panorama da vegetação das restingas do Espírito Santo no contexto do litoral brasileiro. Rev. Eletr. Natureza On Line [Internet]. 2013 [cited jul 2015. 20 Disponível http://www.naturezaonline.com.br/natureza/conteudo/pdf/01_ThomaziRDetal_001006.pdf 